\title{
A lung cancer research agenda that reflects the diverse perspectives of community stakeholders: process and outcomes of the SEED method
}

\author{
Carlin L. Rafie ${ }^{1^{*}}$ (D, Emily B. Zimmerman², Dawn E. Moser ${ }^{3}$, Sarah Cook $^{4}$ and Fatemeh Zarghami ${ }^{1}$
}

\begin{abstract}
Plain English summary
There is a need for methods that engage lay people and other stakeholders, such as patients and healthcare providers, in developing research questions about health issues important to them and their communities. Involving stakeholders helps ensure that funding goes to research that addresses their concerns. The SEED Method engages stakeholders in a systematic process to explore health issues and develop research questions. Diverse groups of stakeholders participate at three levels: as collaborators that lead the process throughout, as participants who use their expertise to develop the questions, and as consultants who provide additional perspectives about the health topic. We used the SEED Method to engage 61 stakeholders from different socioeconomic and professional backgrounds to create research questions on lung cancer outcomes. Participants included cancer patients and caregivers, healthcare providers and administrators, and policymakers from a rural Virginia community. They developed causal models that diagrammed factors that influence lung cancer outcomes and the relationships between them. They used these models to develop priority research questions. The questions reflect the participants' diverse perspectives and address different areas of inquiry related to lung cancer outcomes, including access to care, support systems, social determinants of health, and quality of care. Participants felt well prepared to perform the project tasks because they had the opportunity to review lung cancer information, receive causal model and research question development training, and participate in facilitated group activities. The SEED Method can be used in a variety of settings and applied to any health topic of interest to stakeholders.
\end{abstract}

\begin{abstract}
Background Engagement of stakeholders in prioritization of health research can help ensure that funding is directed to research that reflects their concerns and needs. The Stakeholder Engagement in quEstion Development and Prioritization (SEED) Method is a multi-stakeholder methodology that uses principles of community engagement and causal modeling to develop health research questions that reflect the priorities of patients, clinicians, and other community stakeholders. We conducted a demonstration of the SEED Method to generate research questions on lung cancer outcomes, and to evaluate the process, outcomes, and effectiveness of the method (Continued on next page)
\end{abstract}

\footnotetext{
* Correspondence: crafie@vt.edu

1Department of Human Nutrition, Foods and Exercise, Virginia Polytechnic

Institute and State University, 321 Wallace Hall (0430), 295 West Campus

Drive, Blacksburg, Virginia 24061, USA

Full list of author information is available at the end of the article
}

(c) The Author(s). 2019 Open Access This article is distributed under the terms of the Creative Commons Attribution 4.0 International License (http://creativecommons.org/licenses/by/4.0/), which permits unrestricted use, distribution, and reproduction in any medium, provided you give appropriate credit to the original author(s) and the source, provide a link to the Creative Commons license, and indicate if changes were made. The Creative Commons Public Domain Dedication waiver (http://creativecommons.org/publicdomain/zero/1.0/) applies to the data made available in this article, unless otherwise stated. 
(Continued from previous page)

for generating a research agenda that reflects diverse stakeholder perspectives.

Methods The SEED Method engages community members at three levels: collaboration, participation, and consultation. We conducted a demonstration project from November, 2015 to July, 2016, in a rural Virginia community that was experiencing a significant disparity in lung cancer outcomes. A community research team led the project and selected three distinct stakeholder groups (Topic groups, TG) for participatory engagement in analysis of the health issue, causal modeling, and research question development. We evaluated the quality of stakeholder engagement and compared TG causal models and research questions to evaluate the diversity of stakeholder perspectives resulting from the methodology.

Results The resulting research agenda poses questions on how a broad range of topics including access to care, support systems and coping mechanisms, social determinants of health, and quality of care impacts lung cancer outcomes. Participants felt well prepared for the tasks they were asked to perform due to the technical trainings and facilitated modeling and question development activities that are part of the SEED Method. The causal models and research questions developed by the Topic Groups reflected the diverse perspectives of the stakeholders.

Conclusions The SEED Method has the potential to generate relevant stakeholder-centered research agendas on a variety of health-related topics, and to create community capacity for sustained research engagement.

Keywords: Stakeholder engagement, Research question development, Community based participatory research

\section{Background}

End users of health research are increasingly being engaged throughout the research process. Involvement of those impacted by health issues in the identification and prioritization of research topics allows inclusion of their unique experiential understanding and ensures that research priorities reflect their concerns. [1-3] It also provides opportunities for research that is more valid, relevant, accepted, and sustainable. [3] Various methods for engaging patients and clinicians in topic generation have been used. A systematic review of 148 studies revealed a variety of engagement techniques, including Delphi exercises and face-to-face meetings, and found that all methods engaged participants directly and repeatedly. [4] The majority of studies had clinicians and patients working separately, and most used formal methods for reaching decisions including voting, scoring, individual rating, and consensus conferences. [4]. Best practice recommendations for topic generation processes include ensuring collaboration between patients and clinicians, peer consultations, data analysis, and consensus-building. [5] Recent examples exist of methods that apply these practices, using iterative processes for research topic generation and prioritization with multi-stakeholder research advisory groups and priority setting partnerships [6, 7]. The SEED (Stakeholder Engagement in quEstion Development and Prioritization) Method was developed to fill a gap in stakeholder engagement strategies that are community driven and use participatory methods to engage clinician and patient stakeholders in health research question development and prioritization. $[8,9]$ We conducted a demonstration of the SEED Method with community stakeholders in a rural community in southern Virginia to develop a research agenda relevant to lung cancer outcomes.

A cancer needs assessment conducted by the authors (CR and DM) in this community in 2014 identified a disparity in lung cancer mortality as a significant health issue. [10] Lung cancer is the third most commonly diagnosed cancer and the leading cause of cancer death among both men and women of all races and ethnicities in the United States. [11] The national age-adjusted lung cancer death rate in 2017 was 44.7, compared to 45.5 in Virginia, and 73.1 in the target community for the SEED demonstration. [12] The 5-year survival rate remains very low at only $18.1 \%$. [13] Racial and socioeconomic lung cancer disparities exist and involve complex, interconnected influences of the living environment, behaviors, sociocultural factors, and biology of individuals. [14] The SEED Method is designed to consider the multiplicity of influences on health outcomes using a socio-ecological approach and was conducted as a follow-up to the findings of disparate lung cancer outcomes in the community.

We implemented SEED from November 2015 to July 2016 to explore factors influencing lung cancer outcomes and develop a stakeholder-driven research agenda. We report on the process and outcomes of the SEED Method applied in this context and the effectiveness of the method at generating a research agenda that reflects diverse stakeholder perspectives. 


\section{Methods}

The SEED Method was piloted through funding from the Patient Centered Outcomes Research Institute (PCORI) in a previous project. [15] The method was elaborated by Zimmerman based on a participatory conceptual modeling process that was piloted in two previous projects with colleagues at the Virginia Commonwealth University Center on Society and Health. [16, 17] SEED is founded on community-based participatory research (CBPR) principles and uses causal modeling to facilitate research question development by community stakeholders. It engages stakeholders at three levels; (1) collaborative engagement of a community research team to lead the project throughout the research, (2) participatory engagement with stakeholders working within distinct groups to generate and prioritize research questions, and (3) consultative engagement with stakeholders who add additional perspectives and experiential knowledge to inform the process. [15]

We implemented the SEED Method in a six-step process that first engaged collaborative stakeholders as a community research team. This team managed the project across a period of nine months. The community research team identified targeted groups of stakeholders, called Topic groups (TG), for participatory engagement in the analysis of the health issue and research question development. Other stakeholders, called SCAN participants, were engaged in a consultative fashion to gather additional perspectives about lung cancer outcomes in the local context and inform the TGs as they conceptualized the issue through creation of causal models. Each TG used their model to generate and prioritize research questions. The final step was a review of the scientific literature related to the prioritized research questions by university- and community-based researchers and graduate students to focus the research agendsa on identified research gaps. (Fig. 1) We evaluated the quality of stakeholder engagement in SEED and compared causal models and research questions between TGs to assess the effectiveness of stakeholder engagement in generating distinct research priorities. $[15,18]$ The study was approved by the Virginia Tech IRB, and all participants provided informed consent.

\section{Implementation of the SEED Method in Southern Virginia} The research team (collaborative engagement)

A community research team, Engaging Martinsville (EM), led the project from launch through dissemination. The project coordinator of the previous cancer needs assessment (a community resident) joined the research team and facilitated recruitment of ten additional community members through notifications to community organizations, multimedia advertising, and individual communication. Personal experience with and/or interest in lung cancer and the ability to commit the time to the research team activities were the primary criteria for selection. Individual communication was the most effective means of recruitment. Research team members were paid an hourly wage for the duration of the project. The EM team was diverse in experience, age, and race (36\% white, $55 \%$ black) and was predominately female $(73 \%)$ with an educational attainment above high school (91\%). Three of the team members left before the end of the project due to relocation and changes in work schedule.

EM was involved in all aspects of project management and met weekly throughout the project. Principles of CBPR guided implementation of SEED. [19, 20] In particular, a collaborative and equitable partnership guided the engagement of stakeholders, empowering each member to express their opinions through processes of shared accountability and decision making. These same principles characterized the engagement of TG members in their work.

EM determined the composition of the TGs through a process designed to ensure diversity in experience and perspectives. Briefly, EM used decision aids (SEED stakeholder identification matrices) to identify priority stakeholder subgroups within three general categories: (1) patients and caregivers, (2) healthcare providers, and (3) others. After brainstorming a list of subgroups in each category, the team identified selection criteria that they used to rank the subgroups in order of importance. EM used a voting system to determine the final composition of the TGs. Three TGs were selected. EM then identified appropriate recruitment locations and used fliers, direct communication, and newspaper advertisements to recruit participants. Interested participants were screened for eligibility during a phone conversation. Individuals were advised during the screening of their eligibility status. Newspaper advertisements and direct communication were the two most successful recruiting methods.

\section{The topic groups (participatory engagement)}

The three TGs selected were: (1) lung cancer patients and caregivers (LCP/C, $n=7)$, (2) non-physician clinical

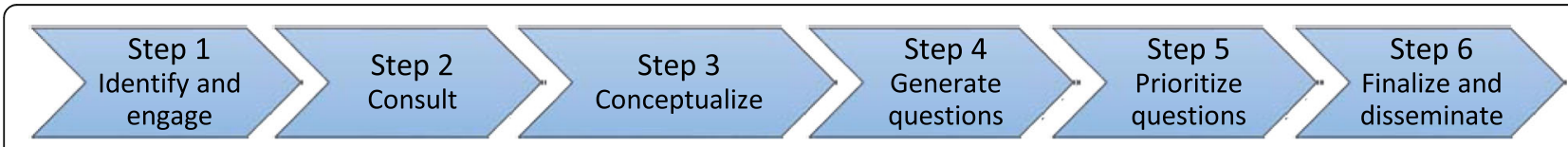

Fig. 1 Steps in the SEED Method (adapted from Zimmerman et al. Am J Prev Med 2017;53(1):123-129) 
care providers $(\mathrm{CCP}, n=8)$ involved in lung cancer patient care, and (3) access influencers (AI, $n=6)$ able to influence access to detection, treatment, and survivorship care. Selection criteria included subgroups with a high prevalence of lung cancer and those residing within the community for the $\mathrm{LCP} / \mathrm{C}$, providers with greater than five years of healthcare experience for the CCP, and significant community involvement and an interest in lung cancer for the AI. TG participants received a stipend for their participation. Three TG members dropped out of the project (one from each group) due to time constraints. Similar to the EM team, TG members were predominantly female (76\%) with greater than a high school education (91\%). TGs had greater representation from adults older than 65 years $(28 \%)$ and people of Caucasian race (62\%) than the EM team.

\section{Topic group activities}

\section{Orientation to the health issue}

TGs each met on seven occasions and worked separately throughout the process. During the first four, 90-min meetings, TGs were oriented to their task and provided information about lung cancer by the EM team. Each TG then identified additional stakeholders (SCAN participants) from whom they wanted information to inform their task. SCAN participants were interviewed or participated in focus groups, and received a stipend for their participation. Ten key informant interviews (physicians, health care service providers, health and lung cancer advocacy organizations, and patients), and four focus groups (lung cancer patients, caregivers, faith leaders, and non-clinician providers) were conducted by the EM Team. Two university-based project members conducted content analysis of the transcripts and summarized the recurring themes. The EM team reviewed the summaries and discussed them with the TGs.

\section{Causal modeling and question development}

Creation of the causal models and research questions occurred during the last three, 180-min TG meetings. Causal models describe the causal mechanisms of a system, and are widely used to propose the interrelationships between dependent and independent variables and moderating and mediating factors. These models can be useful for guiding formulation of research questions and directing future research. [21, 22] TGs received training on causal model development and then participated in a facilitated process of brainstorming factors affecting lung cancer outcomes, positioning those factors in relation to lung cancer outcomes, and depicting causal pathways between factors. Final causal models were created through group discussion and consensus on the factors and their positions within the model. Each TG compared their own model with that of the other two groups.
After a brief training on research question development, TGs drew on the models and the information acquired throughout the project to create research questions around lung cancer outcomes. Question prompts were employed to help generate diverse questions, focusing participants on causes, impacts, verification of relationships, and new directions for thinking about lung cancer outcomes. Each member developed research questions, which were discussed by the group. The TGs then prioritized their research questions through a discussion and multi-voting process. [23] The four highest priority research questions were chosen by each TG to form the final, 12-question research agenda.

\section{Identifying knowledge gaps}

A review team of university and community researchers and graduate students conducted a literature review of the 12 research questions to identify existing evidence and target research gaps. The original research questions were reworded and the review findings were added as additional sub-questions. EM presented the final research agenda to the TGs and the community.

\section{Evaluation}

We evaluated the SEED Method process using questionnaires, activity and observation logs, after action reviews, and participant interviews. Questionnaires were created for this project, but drew on questionnaires published by others. [24-27] Questionnaires included a personal information questionnaire, group readiness and group $d y-$ namics questionnaires completed by the EM team and TGs, and satisfaction questionnaires. Activity and observation logs, as well as the after action reviews, were used to evaluate and improve the SEED process. Activity logs were completed by the activity facilitators after completion of the three stakeholder selection matrices by the EM team, and the causal modeling, question development and prioritization activities of the Topic Groups. Observation logs were completed by a member of the SEED administrative team during these same activities. After action reviews were conducted with TGs after key activities. End of project interviews conducted with EM members evaluated personal and community impact of the project.

To evaluate the diversity of perspectives contributed by each TG, we compared the number and content of factors across the causal models. Two EM members independently grouped factors into categories and reached consensus on category names and factor classification through discussion. Presence and placement of categories and the complexity of linkages between them were also compared.

Research questions were independently grouped into query domains by two EM members to facilitate 
comparison. Consensus on the domain names, and research question grouping was reached through team discussion. We evaluated unique and duplicate question query domains between the TGs and the relationship of research questions to corresponding factors in the respective causal models for each TG.

\section{Results}

\section{Group readiness and dynamics}

Group dynamics is one of four dimensions of CBPR research that can influence project outcomes. [28] We collected group readiness surveys at the beginning of the study and group dynamics at study conclusion. There was consensus among EM and TG participants that they were ready to share openly during the project, their group represented the community, and the project would have personal and community benefit. A majority of respondents felt the group was networked to the community and understood its needs. EM and TG members strongly agreed that there were positive group dynamics with open communication and respect regardless of demographics or socioeconomic status. The majority experienced personal growth and gained new skills through the project. Although most were satisfied with facilitation and decision-making processes, some were ambivalent in this area (Table 1).

Responses to open-ended questions about experiences with the project fell into four categories: respectful sharing of ideas, forming new friends and networks, knowledge gain, and helping the community. TG members expressed satisfaction with the process overall, and EM team members appreciated the group diversity, closeness, and the satisfaction working for their community. There were no major conflicts among members, but the meeting schedule, length and slow pace of some meetings were areas for improvement.

\section{Causal models}

Causal model comparison showed that the clinical care provider (CCP) TG had the greatest number of factors $(n=51)$ and factor categories $(n=19)$, followed by the lung cancer patient and caregiver $(\mathrm{LCP} / \mathrm{C})$ group ( $n=37 \& n=14)$, and the access influencer (AI) group $(n=36 \& n=13)$. A total of 90 factors were identified, of which sixty-four were unique to a single TG, and twenty-six were found in two or more of the models (Table 2).

There were twenty-one categories of factors. Of these, five were unique to one causal model and sixteen were common in two or more causal models. The CCP group had three unique categories (health values, risk factors, and stress), and there was one unique category in the LCP/C (independence) and AI groups (inherited conditions) (Fig. 2). The CCP model had the greatest number of connections between factor (68 connections), followed by the LCP/C model (54 connections), and the AI model (31 connections). Overall, the CCP model showed the greatest complexity, followed by the $\mathrm{LCP} / \mathrm{C}$ model, and lastly the AI model. The LCP/C model is illustrated in Fig. 3.

\section{Research questions}

Each TG created between twenty-one and twentyseven questions. Questions were prioritized and each group selected the top four for inclusion in the final research agenda, for a total of twelve questions. Grouping the final questions into query domains resulted in four domains: Barriers/Access to Care, Support Systems/Coping Mechanisms, Social Determinants of Health, and Quality of Care. The domain, Quality of Care, was unique to the CCP TG, and Support Systems/Coping Mechanisms was unique to the LCP/C TG. All four of the research questions generated by the AI TG fell into the Barriers/Access to Care query domain. The research agenda with the original questions is found in Table 3. The final research agenda with the refined questions and sub-questions generated after the literature review is included in Additional file 1.

\section{Discussion}

The SEED method is unique in that the health issue of interest is community-identified and the method uses causal modeling to inform research question development. It involves diverse stakeholders, including clinicians, patients, and others, in order to generate a diverse research agenda. Similar to other engagement models that separate clinicians and lay people, stakeholder groups work independently to produce and prioritize research questions. The process is conducted within a single community primarily with stakeholders without prior research experience. It engages stakeholders repeatedly through a series of in-person meetings. This contrasts with other methods that solicit input, often electronically, from a large number of different stakeholders in a multi-step process of research topic generation, reduction, and final prioritization, as with priority setting partnerships. [7] Notably, unlike other methods whose primary focus is on clinical care research questions, the SEED Method generates research questions on a wide range of issues related to the health topic.

Sixty-one participants of varying socioeconomic, educational, and professional backgrounds contributed to the lung cancer outcomes research agenda. The process whereby the EM team selected the TGs ensured diverse viewpoints on the problem. This is illustrated by the fact that individual representatives 
Table 1 Engaging Martinsville and Topic Group Member Responses: Group Readiness and Group Dynamics

\begin{tabular}{|c|c|c|c|c|}
\hline Group Readiness & Respondents $^{\mathrm{a}}$ & Strongly Agree & Agree & $\begin{array}{l}\text { Disagree/ Strongly } \\
\text { Disagree }\end{array}$ \\
\hline \multirow[t]{2}{*}{ 1. I am open to learning new skills throughout this project } & $\begin{array}{l}\text { Research } \\
\text { team }\end{array}$ & $72.7 \%$ & $27.3 \%$ & $0.0 \%$ \\
\hline & Topic groups & $81.3 \%$ & $18.8 \%$ & $0.0 \%$ \\
\hline \multirow[t]{2}{*}{$\begin{array}{l}\text { 2. I am willing to share my opinions and life experiences } \\
\text { with other group members. }\end{array}$} & $\begin{array}{l}\text { Research } \\
\text { team }\end{array}$ & $81.8 \%$ & 13.2 & $0.0 \%$ \\
\hline & Topic groups & $87.5 \%$ & $12.5 \%$ & $0.0 \%$ \\
\hline \multirow[t]{2}{*}{$\begin{array}{l}\text { 3. I have a clear picture of the time it will take to be involved } \\
\text { in this project }\end{array}$} & $\begin{array}{l}\text { Research } \\
\text { team }\end{array}$ & $63.6 \%$ & $36.4 \%$ & $0.0 \%$ \\
\hline & Topic groups & $75.0 \%$ & $19.0 \%$ & $0.0 \%$ \\
\hline \multirow[t]{2}{*}{ 4. I understand my role within this project. } & $\begin{array}{l}\text { Research } \\
\text { team }\end{array}$ & $54.5 \%$ & $45.5 \%$ & $0.0 \%$ \\
\hline & Topic groups & $68.8 \%$ & $31.3 \%$ & $0.0 \%$ \\
\hline \multirow[t]{2}{*}{$\begin{array}{l}5 . \text { I am willing to mentor and be mentored throughout } \\
\text { this project. }\end{array}$} & $\begin{array}{l}\text { Research } \\
\text { team }\end{array}$ & $81.8 \%$ & $18.2 \%$ & $0.0 \%$ \\
\hline & Topic groups & $75.0 \%$ & $18.8 \%$ & $6.3 \%$ \\
\hline \multirow[t]{2}{*}{ 6. I believe this project will benefit patients and stakeholders. } & $\begin{array}{l}\text { Research } \\
\text { team }\end{array}$ & $72.7 \%$ & $27.3 \%$ & $0.0 \%$ \\
\hline & Topic groups & $81.3 \%$ & $18.8 \%$ & $0.0 \%$ \\
\hline \multirow[t]{2}{*}{ 7. I believe this project will benefit my community. } & $\begin{array}{l}\text { Research } \\
\text { team }\end{array}$ & $90.9 \%$ & $9.1 \%$ & $0.0 \%$ \\
\hline & Topic groups & $87.5 \%$ & $12.5 \%$ & $0.0 \%$ \\
\hline \multirow[t]{2}{*}{ 8. I think I will benefit from participating in this project. } & $\begin{array}{l}\text { Research } \\
\text { team }\end{array}$ & $100.0 \%$ & $0.0 \%$ & $0.0 \%$ \\
\hline & Topic groups & $81.3 \%$ & $18.8 \%$ & $0.0 \%$ \\
\hline \multicolumn{5}{|l|}{ Group Diversity } \\
\hline \multirow[t]{2}{*}{ 9. Our group reflects the diversity of our community. } & $\begin{array}{l}\text { Research } \\
\text { team }\end{array}$ & $54.5 \%$ & $45.5 \%$ & $0.0 \%$ \\
\hline & Topic groups & $68.8 \%$ & $31.3 \%$ & $0.0 \%$ \\
\hline \multirow[t]{2}{*}{$\begin{array}{l}\text { 10. Our group members are networked to the community } \\
\text { and understand its history, politics, and needs. }\end{array}$} & $\begin{array}{l}\text { Research } \\
\text { team }\end{array}$ & $27.3 \%$ & $72.7 \%$ & $0.0 \%$ \\
\hline & Topic groups & $50.0 \%$ & $37.3 \%$ & $12.6 \%$ \\
\hline \multicolumn{5}{|l|}{ Group Dynamics } \\
\hline \multirow[t]{2}{*}{ 1. I can talk openly and honestly at team meetings. } & $\begin{array}{l}\text { Research } \\
\text { team }\end{array}$ & $81.8 \%$ & $18.2 \%$ & $0.0 \%$ \\
\hline & Topic groups & $82.4 \%$ & $17.6 \%$ & $0.0 \%$ \\
\hline \multirow[t]{2}{*}{$\begin{array}{l}\text { 2. Team members respect each other's point of view } \\
\text { even if they might disagree. }\end{array}$} & $\begin{array}{l}\text { Research } \\
\text { team }\end{array}$ & $100.0 \%$ & $0.0 \%$ & $0.0 \%$ \\
\hline & Topic groups & $82.4 \%$ & $17.6 \%$ & $0.0 \%$ \\
\hline \multirow[t]{2}{*}{$\begin{array}{l}\text { 3. My opinion is listened to and considered by other } \\
\text { team members. }\end{array}$} & $\begin{array}{l}\text { Research } \\
\text { team }\end{array}$ & $100.0 \%$ & $0.0 \%$ & $0.0 \%$ \\
\hline & Topic groups & $82.4 \%$ & $17.6 \%$ & $0.0 \%$ \\
\hline \multirow[t]{2}{*}{$\begin{array}{l}\text { 4. All team members are made to feel welcome regardless } \\
\text { of income, age, race, gender, or education level. }\end{array}$} & $\begin{array}{l}\text { Research } \\
\text { team }\end{array}$ & $100.0 \%$ & $0.0 \%$ & $0.0 \%$ \\
\hline & Topic groups & $88.2 \%$ & $11.8 \%$ & $0.0 \%$ \\
\hline \multirow[t]{2}{*}{ 5. It takes too much time for the team to reach decisions. ${ }^{b}$} & $\begin{array}{l}\text { Research } \\
\text { team }\end{array}$ & $9.1 \%$ & $18.2 \%$ & $82.8 \%$ \\
\hline & Topic groups & N/A & N/A & N/A \\
\hline 6. Everyone in the team has a voice in the decisions. ${ }^{b}$ & $\begin{array}{l}\text { Research } \\
\text { team }\end{array}$ & $90.9 \%$ & $9.1 \%$ & $0.0 \%$ \\
\hline
\end{tabular}


Table 1 Engaging Martinsville and Topic Group Member Responses: Group Readiness and Group Dynamics (Continued)

\begin{tabular}{|c|c|c|c|c|}
\hline Group Readiness & Respondents $^{\mathrm{a}}$ & Strongly Agree & Agree & $\begin{array}{l}\text { Disagree/ Strongly } \\
\text { Disagree }\end{array}$ \\
\hline & Topic groups & N/A & N/A & $\mathrm{N} / \mathrm{A}$ \\
\hline \multirow[t]{2}{*}{$\begin{array}{l}\text { 7. Some members of the team hold onto their ideas } \\
\text { too tightly. }{ }^{b}\end{array}$} & $\begin{array}{l}\text { Research } \\
\text { team }\end{array}$ & $18.2 \%$ & $0 \%$ & $81.8 \%$ \\
\hline & Topic groups & N/A & N/A & N/A \\
\hline \multicolumn{5}{|l|}{ Benefits/Costs of Participation } \\
\hline \multirow[t]{2}{*}{$\begin{array}{l}\text { 8. Participating in this project has provided personal } \\
\text { growth for me. }\end{array}$} & $\begin{array}{l}\text { Research } \\
\text { team }\end{array}$ & $90.9 \%$ & $9.1 \%$ & $0.0 \%$ \\
\hline & Topic groups & $90.9 \%$ & $9.1 \%$ & $0.0 \%$ \\
\hline \multirow[t]{2}{*}{$\begin{array}{l}\text { 9. Since starting to work on this project, my skills and } \\
\text { knowledge have increased. }\end{array}$} & $\begin{array}{l}\text { Research } \\
\text { team }\end{array}$ & $81.8 \%$ & $18.2 \%$ & $0.0 \%$ \\
\hline & Topic groups & $81.8 \%$ & $18.2 \%$ & $0.0 \%$ \\
\hline \multicolumn{5}{|l|}{ Understanding of the SEED Method } \\
\hline \multirow[t]{2}{*}{ 10. I understand my role in the SEED project } & $\begin{array}{l}\text { Research } \\
\text { team }\end{array}$ & $81.8 \%$ & $18.2 \%$ & $0.0 \%$ \\
\hline & Topic groups & $76.5 \%$ & $23.5 \%$ & $0.0 \%$ \\
\hline Group decision making process & & Very satisfied/ satisfied & Unsure & Dissatisfied/very dissatisfied \\
\hline \multirow[t]{2}{*}{ 11. Satisfaction with meeting facilitation } & $\begin{array}{l}\text { Research } \\
\text { team }\end{array}$ & $81.8 \%$ & $18.2 \%$ & $0.0 \%$ \\
\hline & Topic groups & $76.5 \%$ & $23.5 \%$ & $0.0 \%$ \\
\hline \multirow[t]{2}{*}{ 12. Satisfaction with how team works } & $\begin{array}{l}\text { Research } \\
\text { team }\end{array}$ & $90.9 \%$ & $9.1 \%$ & $0.0 \%$ \\
\hline & Topic groups & $82.4 \%$ & $17.6 \%$ & $0.0 \%$ \\
\hline \multirow[t]{2}{*}{ 13. Satisfaction with decision making process ${ }^{b}$} & $\begin{array}{l}\text { Research } \\
\text { team }\end{array}$ & $81.8 \%$ & $18.2 \%$ & $0.0 \%$ \\
\hline & Topic groups & N/A & N/A & N/A \\
\hline \multirow[t]{2}{*}{ 14. Satisfaction with way team deals with problems } & $\begin{array}{l}\text { Research } \\
\text { team }\end{array}$ & $81.8 \%$ & $18.2 \%$ & $0.0 \%$ \\
\hline & Topic groups & $70.6 \%$ & $29.4 \%$ & $0.0 \%$ \\
\hline
\end{tabular}

${ }^{\mathrm{a}}$ Research Team $(n=11)$, and Topic Groups ( $n=16$ for questions $1-10, n=18$ for group dynamics questions $\left.1-14\right)$

${ }^{\mathrm{b}}$ These questions were irrelevant to the Topic groups, and were not included on the abbreviated group dynamics questionnaire

within each group fell into five of the seven stakeholder categories outlined in the 7Ps Framework for Stakeholder Engagement, including patients and the public, providers, purchasers, payers, and policy makers. [29] Each TG worked independently to highlight their unique experiences and to ensure that questions from each group were included in the final research agenda. Topic groups comprised of similar stakeholders helped facilitate group cohesion and open expression, and aimed to avoid power differentials that are common among mixed patient and provider groups.

We evaluated the quality of stakeholder engagement and compared the final products (causal models and research questions) developed by the different stakeholder groups to assess the effectiveness of the SEED Method in facilitating distinct stakeholder contributions. [4, 18] Our comparison of the TG causal models and research questions illustrates the unique perspectives that each brought to the health issue. A large proportion of factors (71\%) in the causal models were unique to individual TGs, and the position of factor categories and number of connections between them varied between groups.

TG research questions fell into unique query domains and addressed distinct issues. For example, the $\mathrm{LCP} / \mathrm{C}$ TG prioritized a research question about the intersection of faith and lung cancer outcomes (see Table 3). "Faith in God" was a unique factor in their causal model and they had unique discussions exploring the relationship of faith to coping with lung cancer, decision making and risk taking, and lung cancer outcomes. The 'Religiosity' category was positioned early in their model and contained ten connections to other factor categories, highlighting its importance from their perspective. This question fell into the query domain Support Systems/Coping Mechanisms, which was unique to this TG. 
Table 2 Causal Model Factor Comparison

\begin{tabular}{|c|c|c|c|}
\hline \multicolumn{3}{|l|}{ Unique Factors } & \multirow{2}{*}{$\begin{array}{l}\text { Factors Common to Two } \\
\text { or More Groups }\end{array}$} \\
\hline $\begin{array}{l}\text { Lung Cancer Patients and Caregivers } \\
\text { (LCP/C) }\end{array}$ & Clinical Care Providers (CCP) & Access Influencers (Al) & \\
\hline Body weight & Access to care & Addictions & Affordability of care \\
\hline Community support & Alternative health care & Availability of medications & Age \\
\hline Exercise & Cancer stage & Delayed or misdiagnosis & Availability of care \\
\hline Faith in God & Community involvement & Drinking alcohol & Communication ability \\
\hline Fitness & Co-morbid conditions & Family size & Coordination of care \\
\hline Follow up care & Computer literacy & Fear & Denial \\
\hline Food quality & Coping skills & Immigration status & Getting information \\
\hline Having a regular doctor & Culture & Inherited conditions & Hope \\
\hline Household cleaning & Education on treatment options & Insurance status & Income \\
\hline Leisure activities & Family dysfunction & Lack of education on cancer symptoms & Literacy \\
\hline Maintaining independence & Financial support & Mindfulness & Mental health \\
\hline Pain management & Genetic testing & Religion & Pain \\
\hline Place & Health literacy & Social programs & Physical health \\
\hline Quitting smoking & Housing & Specialized care & Positivity \\
\hline Second-hand smoke & IQ & & Prayer \\
\hline Sense of control & Marital status & & Quality of care \\
\hline Trust in doctor & Pollution & & Religious practices \\
\hline \multirow[t]{15}{*}{ Willingness to take risks } & Procrastination & & Smoking/quitting \\
\hline & Quality of death & & Social policies \\
\hline & Quality of life values & & Social values \\
\hline & Race/ethnicity & & Sources of information \\
\hline & Resistance to medical model & & Support for caregivers \\
\hline & Resource management & & Support from family \\
\hline & Risk factors & & Transportation \\
\hline & Screening & & Use of care \\
\hline & Self-care & & $\begin{array}{l}\text { Occupational health/work } \\
\text { conditions }\end{array}$ \\
\hline & Stress & & \\
\hline & Transportation & & \\
\hline & Trust & & \\
\hline & Urban/rural & & \\
\hline & Will to live & & \\
\hline & Willingness to ask for help & & \\
\hline
\end{tabular}

In a similar way, the Quality of Care query domain was unique to the CCP TG. The two research questions in this domain related to unique factors in the group's causal model:

"Would more assistance navigating the healthcare system improve outcomes?" (Unique Factor: education on treatment options)

"If we could affect perceptions of care at local hospitals and providers, would it change lung cancer outcomes?" [Unique Factor: trust]
CCP had unique discussions on the need for specialized navigation services for patients with limited knowledge of cancer treatments, and the impact of negative perceptions and distrust of local healthcare on healthcare seeking behavior. Timeliness of lung cancer diagnosis and treatment were identified as important factors in lung cancer outcomes.

Finally, all four questions of the AI TG fell in the query domain, Barriers/Access to Care. The occupational focus of AI members on facilitating care access is reflected in their prioritization of research questions that address this domain. 


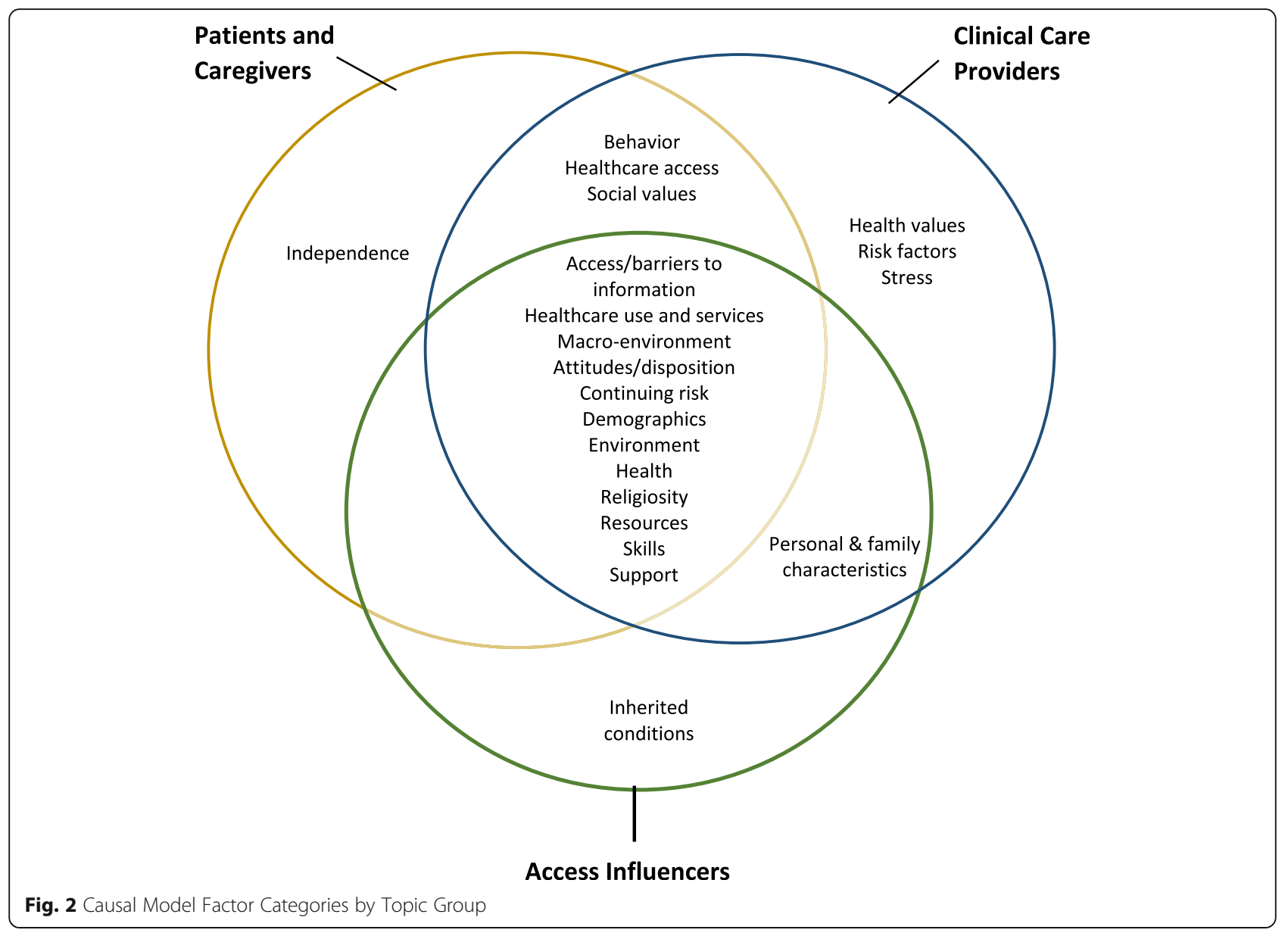

Stakeholders define engagement as the active decision-making of committed stakeholders about a problem that is meaningful to them through a process of respectful interactions where everyone's opinions are heard and carry weight. [30] The positive responses on the surveys are evidence that the SEED Method fostered equitable engagement and avoided many of the pitfalls of group dynamics.
A lack of technical training and capacity building in stakeholder engagement methodologies for collaborative research question development are common limitations. [31-33] Time to review data and discuss ideas, along with trainings in causal modeling and research question development that are part of SEED, address these limitations. The majority of stakeholders in this project felt well prepared for the tasks they were asked to perform.

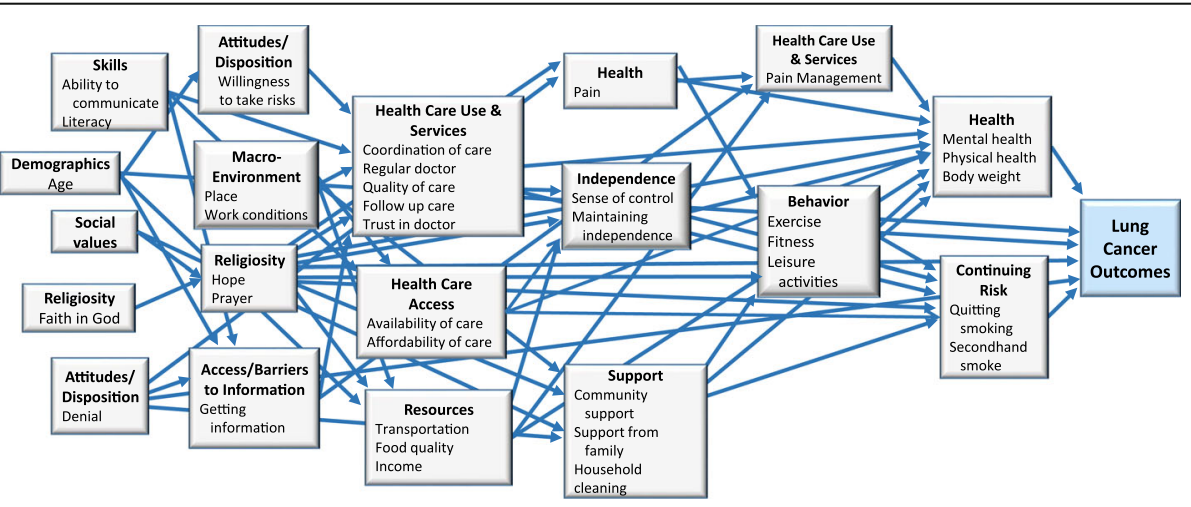

Fig. 3 Lung Cancer Patient and Caregiver Topic Group Causal Model 
Table 3 Final Topic Group Research Questions

Cancer Patient and Caregiver Topic Group
1. What are the factors of patients' faith (for example, knowing what
happens when you die, feeling of peace or seeing family members
again) and knowing family and community are praying for them;
and how does this affect lung cancer outcomes? Does it reduce
stress and does it change their outlook? (Support Systems/Coping
Mechanisms)
2. Does living in a poverty stricken area versus an area of higher
standards affect lung cancer? (Social determinants of health)
3. Why is there no help available through the healthcare system to
discuss alternative treatments, natural choices, diet and nutrition?
(Barriers/Access to care)
4. If society required insurance companies to offer free annual
checkups with x-rays would lung cancer be diagnosed earlier?
(Barriers/Access to care)
Clinical Care Providers Topic Group
5. If we could affect perceptions of care at local hospitals and
providers, would it change outcomes? (Quality of care)
6. Would more assistance navigating the healthcare system improve
outcomes? (Quality of care)
7. If we could improve the general health of the population would
it affect lung cancer outcomes? (Social determinants of care)
8. If patients knew more about hospice goals and palliative care,
would it affect treatment decisions and outcomes? (Barriers/Access
to care)
Access Influencers Topic Group
9. If screenings and early detection occur, does MHMHC, Memorial
Hospital of Martinsville and Henry County (local hospitals), have the
resources and technology to provide efficient and expedited
methods to diagnose and stage? (Barriers/Access to care)
10. If healthcare insurance coverage was standardized for diagnosis
and treatment of cancer, would lung cancer outcomes become
better? (Barriers/Access to care)
11. Would paid FMLA (Family Medical Leave Act) legislation for
caregivers benefit lung cancer outcomes and how? (Barriers/
Access to care)
12. If the Primary Care Physician recommended regular screening, the
patient met qualifying guidelines, and the cost was covered,
would they have the screening? What are the reasons why not?
Would it change the lung cancer outcomes? (Barriers/Access to
care)

\section{Limitations}

The process length and time commitment were areas for improvement. We completed project activities (excluding the literature review) in nine months; TG activities occurred in months three through six. A shortened timeline could broaden the application of the method. A SEED Method toolkit has been developed that accommodates varying timelines according to project-specific objectives. Although our findings indicate a high degree of stakeholder satisfaction with the SEED process and effective stakeholder engagement, these results may vary depending on the context, experience, and relationships of university-community research teams.

It is important that a dissemination plan for the research agenda be part of stakeholder engagement projects and systems in order to link resulting research priorities to potential funders. This has been the process in multiple studies and public-clinician partnerships [5-
7], and was part of our process. The project findings and final research agenda were disseminated to the community through two public presentations. We also presented the final research agenda to health researchers at two state universities, resulting in a doctoral research project conducted in the community evaluating patient and physician barriers to lung cancer screening. A number of the research questions are under review by AHRQ's Effective Healthcare Program for an evidence review to help inform patient, clinician, and health system decision making. [34] In addition, the local hospital has taken several actions in response to the project, including implementation of a physician education campaign to increase lung cancer screening referral and systems to increase access to low dose CT to vulnerable populations.

\section{Conclusion}

The SEED Method effectively engaged community stakeholders in the development of a patient-centered research agenda to address lung cancer outcomes. Participants with diverse viewpoints brought a range of perspectives on the social and environmental factors affecting health behaviors, decision making, and health outcomes. The SEED Method has the potential to generate stakeholder-centered research agendas on a variety of health-related topics and to create community capacity for sustained research engagement.

\section{Additional file}

Additional file 1: Final Stakeholder Developed Research Agenda on Lung Cancer outcomes. The final lung cancer outcome research agenda with the refined questions and sub-questions generated after the literature review. (PDF $112 \mathrm{~kb}$ )

\section{Abbreviations}

Al: Access influencers; CBPR: Community-based participatory research; CCP: Non-physician clinical care providers; EM: Engaging Martinsville; LCP/ C: Lung cancer patients and caregivers; SCAN: Consultative stakeholders; SEED: Stakeholder Engagement in Research Questions Development and Prioritization; TG: Topic Group

\section{Acknowledgements}

The authors thank the Engaging Martinsville team members who helped lead the project. The authors also express deep appreciation for the participation of those stakeholders who were members of Topic groups and those who took part in the focus groups and interviews. Finally, we would like to acknowledge the support provided to the project by Sovah Health, and the New College Institute in Virginia, as well as content experts who reviewed and the revised research questions after the literature review had been completed.

\section{Funding}

Research reported in this article was funded through a Patient-Centered Outcomes Research Institute (PCORI) Award (ME-1310-07664). The statements in this article are solely the responsibility of the authors and do not necessarily represent the views of PCORI, its Board of Governors, or Methodology Committee. PCORI had no role in study design; collection, analysis, and 
interpretation of data; writing the report; or the decision to submit the report for publication.

\section{Availability of data and materials}

The datasets used and/or analyzed during the current study are available from the corresponding author on reasonable request.

\section{Authors' contributions}

CR supervised all study activities, was involved in all aspects of the study including co-facilitation of engagement activities, data acquisition, analysis and interpretation, and manuscript preparation. EZ was responsible for study conception and design, co-facilitated engagement activities, was involved in data acquisition, analysis and interpretation, and manuscript review and editing. SC was involved in the study design, data acquisition and interpretation and manuscript review and editing. FZ was involved in data acquisition, analysis and interpretation, manuscript review and editing. All authors read and approved the final manuscript

\section{Ethics approval and consent to participate}

This research was approved by the Virginia Tech Institutional Review Board. IRB Approval \# 15-748.

All participants provided written informed consent

\section{Consent for publication}

Not applicable.

\section{Competing interests}

The authors declare that they have no competing interests.

\section{Publisher's Note}

Springer Nature remains neutral with regard to jurisdictional claims in published maps and institutional affiliations.

\section{Author details}

${ }^{1}$ Department of Human Nutrition, Foods and Exercise, Virginia Polytechnic Institute and State University, 321 Wallace Hall (0430), 295 West Campus Drive, Blacksburg, Virginia 24061, USA. ${ }^{2}$ Center on Society and Health, Virginia Commonwealth University, 830 East Main St., Suite 5032, P.O. Box 980212 , Richmond, Virginia 23298-0159, USA. ${ }^{3}$ Martinsville, Virginia 24112, USA. ${ }^{4}$ Vanderbilt Institute for Clinical and Translational Research (VICTR), Vanderbilt University Medical Center, 2525 West End Ave, Nashville, TN 37203, USA.

\section{Received: 9 August 2018 Accepted: 29 November 2018}

Published online: 11 January 2019

\section{References}

1. Kapiriri L, Norheim OF. Whose priorities count? Comparison of communityidentified health problems and burden-of-disease assessed health priorities in a district in Uganda. Health Expect. 2002;5:55e62.

2. Lomas J, Fulop N, Gagnon D, Allen P. On being a good listener: setting priorities for applied health services research. Milbank Q. 2003:81(3):363e88.

3. Bowling A, Jacobson B, Southgate L. Explorations in consultation of the public and health professionals on priority setting in an inner London health district. Soc Sci Med. 1993;37(7):81e7.

4. Stewart RJ, Caird J, Oliver K, Oliver S. Patients' and clinicians' research priorities. Health Expectations: An International Journal of Public Participation in Health Care and. Health Policy. 2011;14(4):439-48.

5. Nass $P$, Levine $S$, Yancy C. Methods for involving patients in topic generation for patient-centered comparative effectiveness research: an international perspective. In: Research priorities White paper (PCORISOLRPWG-001) for the Patient-Centered Outcomes Research Institute (PCORI); 2012. https://www.pcori.org/sites/default/files/Methods-forInvolving-Patients-in-Topic-Generation-for-Patient-Centered-ComparativeEffectiveness-Research-\%E2\%80\%93-An-International-Perspective.pdf. Accessed 7 July 2017.

6. Haynes SC, Rudov L, Nauman E, Hendryx L, Angove RSM, Carton T. Engaging stakeholders to develop a patient-centered research agenda. 2018;56:S2-S32.

7. Madden M, Morley R. Exploring the challenge of health research priority setting in partnership: reflections in the methodology used by the James
Lind Alliance pressure ulcer priority setting partnership. Research Involvement and Engagement. 2016;2:12.

8. Macaulay AC, Commanda LE, Freeman WL, Gibson N, McCabe ML, Robbins CM, et al. Participatory research maximises community and lay involvement. North American primary care research group. BMJ. 1999:319:774-8.

9. MacFarlane A, Galvin R, O'Sullivan M, Mclnerney C, Meagher E, Burke D, et al. Participatory methods for research prioritization in primary care: an analysis of the world Café approach in Ireland and the USA. Fam Pract. 2017;34(3):278-84. https://doi.org/10.1093/fampra/cmw104.

10. Massey Cancer Center, Cancer needs assessments TICRC-funded projects. http:// massey.vcu.edu/research/highlights/ticrc-funded-projects. Accessed 6 August 2018.

11. U.S. Cancer Statistics Working Group United States Cancer Statistics: 1999-2014 Incidence and Mortality Web-based Report. Atlanta: U.S. Department of Health and Human Services, Centers for Disease Control and Prevention and National Cancer Institute; 2017. Available at: www.cdc.gov/uscs.

12. State Cancer Profiles, National Cancer Institute, Centers for Disease Control. https://statecancerprofiles.cancer.gov/map/map.withimage. php?51\&001\&047\&00\&0\&02\&0\&1\&5\&0\#results. Accessed on July 7, 2017.

13. SEER stat fact sheets: Lung and Bronchus Cancer (n.d.) National Cancer Institute: Surveillance, Epidemiology, and End Results Program http://seer. cancer.gov/statfacts/html/lungb.html. Accessed on July 7, 2017.

14. Zonderman AB, Ejiogu N, Norbeck J, Evans MK. The influence of health disparities on targeting Cancer prevention efforts. Am J Prev Med. 2014; 46(301):S87-97. https://doi.org/10.1016/j.amepre.2013.10.026.

15. Zimmerman EB, Cook SK, Haley AD, Woolf SH, Price SK. A patient and provider research agenda on diabetes and hypertension management. Amer J Prev Med. 2017. https://doi.org/10.1016/j.amepre.2017.01.034.

16. Woolf $\mathrm{SH}$, Braveman P, Evans BF. The health implications of reduced food stamp eligibility. Richmond, Virginia Commonwealth University, Center on Human Needs; 2013

17. Zimmerman EB, Woolf SH, Haley A. Understanding the relationship between education and health: a review of the evidence and an examination of community perspectives. In: Kaplan RM, Spittel ML, David DH, editors. Population health: behavioral and social science insights. Rockville: Agency for Healthcare Research and Quality; 2015. p. 347-84.

18. Davison K, D'Andreamatteo C, Mitchell S, Vanderkooy P. The development of a national nutrition and mental health research agenda with comparison of priorities among diverse stakeholders. Public Health Nutr. 2017;20(4):712-25.

19. Israel BA, Schulz AJ, Parker EA, Becker AB. Review of community-based research: assessing partnership approaches to improve public health. Annu Rev Public Health. 1998;19:173-202.

20. Minkler M, Wallerstein N, editors. Community-Based Participatory Research for Health: From Process to Outcomes ( $2^{\text {nd }}$ edition). San Francisco: Jossey-Bass; 2008.

21. Diez Roux AV. Conceptual approaches to the study of health disparities. Annu Rev Public Health. 2012;33:41-58 https://doi.org/10.1146/annurevpublhealth-031811-124534

22. Paradies $Y$, Stevens M. Conceptual diagrams in public health research. J Epidemiol Community Health. 2005;59(12):1012-3. https://doi.org/10.1136/ jech.2005.036913.

23. Tague NR. The Quality Toolbox, (2 ${ }^{\text {nd }}$ edition). Milwaukee: ASQ Quality Press; 2004.

24. Community-Engaged (CE) research survey instrument/data Matrix 2012. https://cpr.unm.edu/common/docs/CommunityEngagement\%20Data\%20collection\%20Instrument\%20Matrix.pdf

25. Israel BA, Lantz PM, McGranaghan RJ, Kerr DL, Guzman JR. Detroit community academic urban research center closed ended survey questionnaire for board evaluation. In: Israel BA, Eng E, Schultz AJ, Parker EA, editors. Methods in community based participatory research for health. San Francisco: Jossey-Bass; 2005. p. 430-3. p. Appendix H.

26. Sandoval JA, Lucero J, Oetzel J, Avila M, Belone L, Mau, et al. Process and outcome constructs for evaluating community-based participatory research projects: a matrix of existing measures. Health Educ Res. 2012;27(4):680-90.

27. Wolff T. A practical approach to evaluating coalitions. In: Backer T, editor. Evaluating community collaborations. New York: NY Springer Publishing; 2003.

28. Wallerstein N, Oetzel J, Duran B, Tafoya G, Belone L, Rae R. What predicts outcomes in CBPR? Meredith Minkler, and Nina Wallerstein (eds), Community-Based Participatory Research for Health: From Process to Outcomes. Incorporated: John Wiley \& Sons; 2008. 
29. Concannon TW, Meissner P, Grunbaum JA, McElwee N, Guise JM, Santa J, et al. A new taxonomy for stakeholder engagement in patient centered outcomes research. J Gen Intern Med. 2012;27:985-91.

30. Norris JM, White DE, Nowell L, Mrklas K, Stelfox HT. How do stakeholders from multiple hierarchical levels of a large provincial health system define engagement? A qualitative study. Implementation Science : 1S. 2017;12:98. https://doi.org/10.1186/s13012-017-0625-5.

31. Oliver $S$, Clarke-Jones $L$, Rees $R$, et al. Involving consumers in research and development agenda setting for the NHS: developing an evidence based approach. Health Technol Assess. 2004;8(15):1-148.

32. O'Haire C, McPheeters M, Nakamoto EK, LaBrant L, Most C, Lee K, et al. Engaging Stakeholders to Identify and Prioritize Future Research Needs. Methods Future Research Needs Reports, no. 4. Rockville: Agency for Healthcare Research and Quality; 2011.

33. Hoffman A, Montgomery R, Aubry W, Tunis SR. How best to engage patients, doctors, and other stakeholders in designing comparative effectiveness studies. Health Aff (Millwood). 2010. https://doi.org/10.1377/ hlthaff.2010.0675.

34. Agency for Healthcare Research and Quality. https://effectivehealthcare. ahrq.gov/get-involved/suggest-topic. Accessed 8 August 2018.

Ready to submit your research? Choose BMC and benefit from:

- fast, convenient online submission

- thorough peer review by experienced researchers in your field

- rapid publication on acceptance

- support for research data, including large and complex data types

- gold Open Access which fosters wider collaboration and increased citations

- maximum visibility for your research: over $100 \mathrm{M}$ website views per year

At $\mathrm{BMC}$, research is always in progress.

Learn more biomedcentral.com/submissions 